\title{
Experimental and FEM Analysis of Wear Behaviour in AA5083 Ultrafine-Grained Cams
}

\author{
C. J. Luis Pérez*, R. Luri Irigoyen, J. P. Fuertes Bonel, J. León Iriarte, D. Salcedo Pérez and \\ I. Puertas Arbizu
}

Materials and Manufacturing Engineering Research Group, Engineering Department, Public University of Navarre, Campus Arrosadía s/n, 31006 Pamplona, Navarra, Spain; rodrigo.luri@unavarra.es (R.L.I.); juanpablo.fuertes@unavarra.es (J.P.F.B.); javier.leon@unavarra.es (J.L.I.); daniel.salcedo@unavarra.es (D.S.P.); inaki.puerta@unavarra.es (I.P.A.)

* Correspondence: cluis.perez@unavarra.es; Tel.: +34-948-169-301

Received: 9 March 2020; Accepted: 2 April 2020; Published: 4 April 2020

\begin{abstract}
Severe plastic deformation (SPD) processes have attracted a great deal of both scientific and technological interest over the last few years as a consequence of the improvements that are possible to obtain in the microstructure and mechanical properties of the materials manufactured through the use of these kind of processes. However, the practical applications of such materials to obtain mechanical components are significantly fewer. As a direct consequence, the same thing has been observed in the development of studies that show the in-service behaviour of the mechanical components developed in this way. Since one of the industrial objectives of these SPD processes is to obtain functional parts, it is necessary to carry out studies to fill this gap. Therefore, in this study, an analysis of the wear that cams undergo when manufactured from an AA5083 aluminium-magnesium alloy is carried out. The cams were isothermally-forged from materials with and without previous SPD processing by equal channel angular pressing (ECAP). Subsequently, the wear behaviour of these cams was analysed by using specific equipment, which may have been considered to have a block-on-ring configuration, developed for testing in-service wear behaviour of mechanical parts. From this comparative wear study with cams, it is shown that previously-processed materials by ECAP have a better wear performance. Moreover, finite element modelling (FEM) simulations were also included to predict wear in the cams processed in this way. A good agreement between FEM and experimental results was obtained. It is this aspect of performing the wear tests on functional and real mechanical components, and not on laboratory samples, which makes this present research work novel.
\end{abstract}

Keywords: isothermal forging; wear; ECAP; FEM; aluminium

\section{Introduction}

Over the last few years, there has been a growing interest in the development of ultrafine-grained materials (UFG) as a consequence of the improvement in their mechanical properties, compared to those obtained in a non-nanostructured state [1]. These properties make these materials attractive for potential industrial applications [2]. One of the main ways to obtain bulk ultrafine-grained materials is by means of severe plastic deformation (SPD) processes, where equal channel angular pressing (ECAP) is one of the main processes used to obtain these materials. This process has several innovative technological characteristics compared to traditional metal-working processes [3]. It consists of the extrusion of a material by employing a die that has two channels that intersect at an angle usually comprised between $90^{\circ}$ and $120^{\circ}$ [4]. Moreover, it is possible to obtain bulk ultrafine-grained materials 
with SPD processes that do not use an angular channel such as high-pressure torsion (HPT) [5], repetitive corrugation and straightening (RCS) [6], and high-pressure torsion extrusion (HPTE) [7].

One of the main advantages of SPD processes is the possibility to obtain bulk materials that can be used to develop mechanical components with improved properties. In this way, Kim et al. developed micro-gears from ECAP'ed AA6061 at 443 and $553 \mathrm{~K}$ by using the forward extrusion [8]. These authors found that this forward extrusion process could be carried out without a significant loss of the mechanical properties which had been previously developed by ECAP [8]. In a study by Luis Pérez et al. [9], two gears, with different modules, made of AA5083 after ECAP were obtained; an improvement in the microhardness of approximately $13.6 \%$ was observed with respect to that obtained in the gears developed by forging of the annealed AA5083, and, in a study by Lee et al. [10], a magnesium alloy impeller with twisted blades and an ultrafine grain size was analysed. Some other research works have studied the effect of ECAP on the wear properties of parts manufactured in this way. However, the number of these studies was far lower than those research studies that dealt with the mechanical and microstructural properties of these materials. Among these studies, that by Ortiz et al. [11] analysed the effect of the severe plastic deformation on the tribological properties of the so-processed materials by ball-on-disk tests. These authors analysed the sliding wear resistance in an Al-Mg-Si alloy that was previously-processed by ECAP. They found that the wear resistance increased as the number of ECAP passages was also increased. The research work by Thiyaneshwaran and Sureshkumar [12] studied the wear behaviour of the AA5083 before and after being processed twice by ECAP with the Bc route at room temperature. This study analysed the influence of ECAP on the microstructure, mechanical properties, and wear resistance of the chosen alloy. The authors found that the wear resistance increased due to the refinement of the grain size obtained by ECAP [12]. In a study by Chegini et al. [13], AA7075 was processed by ECAP using route Bc. In order to study wear behaviour, these authors carried out tests with a piece of pin-on-disk equipment using different loads and sliding velocities. The authors carried out a study of the effect of ECAP processing on wear by using scanning electron microscopy (SEM) and transmission electron microscopy. They concluded that wear resistance was increased in the ultrafine-grained material. Likewise, they indicated that the main wear mechanism could be attributed to adhesive wear and delamination [13].

Some other studies have analysed the effect of ECAP processing on wear in materials others than aluminium alloys. For example, in the research work by Li et al. [14], the wear resistance of a copper zirconium alloy processed by ECAP was studied. To this end, ball-on-disc tests were carried out on specimens with both annealed and ECAP'ed materials. They found that ECAP processing led to a decrease in wear depth and wear volume loss [14]. In a study by Luri et al. [15], the wear behaviour of connecting-rods obtained from material that was previously-processed by ECAP was analysed. This behaviour was compared to that obtained from material forged from an annealed state. A better wear resistance was obtained in the materials that were previously-processed by ECAP than that obtained in not previously ECAP'ed materials [15]. On the other hand, Avcu [16] analysed the dry sliding behaviour of an ECAP-processed AA7075 aluminium alloy and found that the coefficient of friction, the volume loss, the mass loss and the specific wear rate were increased with ECAP. In regard to finite elements simulations, most of results found in the literature to model wear behaviour have been developed for specific tribological systems (two materials in particular, a specific contact geometry and for a specific environment and lubricant). Moreover, operational conditions have usually also been stated. Among many other studies, in the research work by Wang et al. [17], the mechanism of erosion in ductile and fragile metals was studied. In the work of Spiegelberg and Andersson [18], wear simulations were based on a generalized form of the Archard wear model, and in the research study by Shirzadegan et al. [19], a numerical model was developed in order to simulate contacts with elastohydrodynamic lubrication in cam mechanisms.

Several studies have dealt with improvements in the mechanical properties of materials obtained by using SPD. However, the number of research studies that have dealt with the development of mechanical components, as well as the number of studies that have analysed the in-service behaviour 
of such developed parts, is significantly lower. Therefore, this present research study aimed to fill this gap, and it presents some results obtained from an experimental analysis of the wear undergone by a mechanical components of the cam type; these components were tested by using equipment with a block-on-ring configuration that was specifically developed for testing the in-service wear behaviour of such mechanical parts. The wear tests for the functioning of the cams were designed as accelerated wear tests where these cams are intended to be used to give movement to the valves of traditional combustion engines.

Though there have been some studies where wear tests have been carried out on samples extracted from the original ECAP'ed billets of aluminium alloys, in this present research study, the wear tests were performed on functional parts-in this case, a cam that had been manufactured from an ECAP'ed aluminium alloy (AA5083) by a forging process. It is considered that this difference between the present study and other previous ones is really important, and it is this aspect of performing the wear tests on functional and real mechanical components and not on laboratory samples that makes it novel. The aluminium alloy that was employed (AA5083) was isothermally-forged to obtain the cams from both annealed material and previously ECAP-processed material. In addition, FEM simulations were included in order to model material wear. A comparative analysis between both FEM and experimental results is also included in this present study.

\section{Set-Up of the Experiment}

An aluminium-magnesium alloy (AA-5083) was studied in this research work. First, it was subjected to a heat treatment of annealing that consisted of a heating slope over $1 \mathrm{~h}$ up to a temperature of $345^{\circ} \mathrm{C}$ that was maintained over $2 \mathrm{~h}$, followed by a final slow cooling down to room temperature inside the furnace. This aluminium alloy was then isothermally-forged to obtain mechanical components of the cam type. The wear behaviour that the cams undergo when manufactured in this manner was analysed. Two initial states were considered: an annealed material and an ECAP-processed material that had been previously subjected to the annealing process. The grain size of the ECAP-processed material fell within the submicrometric range. This refinement in the grain size has been widely studied and is due to the introduction of high strain values in the material. At the same time, mechanical properties such as hardness, yield strength, tensile strength, and fatigue strength are improved. Moreover, depending on the process conditions, forgeability may also be improved.

This ECAP processing was carried out by using an extrusion press at the Public University of Navarre (Spain). The ECAP die had a circular cross-section with a diameter of $20 \mathrm{~mm}$, and it had a configuration of equal fillet radii with a value of $5 \mathrm{~mm}$. The angle between the entrance channel and the exit channel was $90^{\circ}$. Two ECAP passages were carried out at room temperature by using route C, where this route consists in rotating the material billet $180^{\circ}$ after each passage. Then, these parts were isothermally-forged to manufacture the cams. This isothermal forging process was also carried out on this aluminium alloy but with an annealed microstructure as the starting material in order to compare the results obtained. The microstructure and the mechanical properties of this aluminium alloy before and after ECAP processing can be found in a research study by León et al. [20] (see Figure 1), where a new flow stress that is valid for both a wide temperature range and different initial deformation conditions in the starting material was also proposed.

As can be observed in Figure 1, the effects of ECAP on isothermal forging were beneficial in terms of microstructure and mechanical properties. The forging of the ECAP-processed AA5083 produced a finer and more homogeneous microstructure in the manufactured cam in relation to the forging of the annealed AA5083. In the case of the cam under consideration in this study, an increase from 107.5 to $118.6 \mathrm{HV}$ (that is, of $10.3 \%$ ) was obtained in the microhardness mean value. In addition, the annealed AA5083 had a mean grain size of $200 \mu \mathrm{m}$, and the ECAP-processed material from the forged cam had a grain size as fine as $250 \mathrm{~nm}$ [21]. 


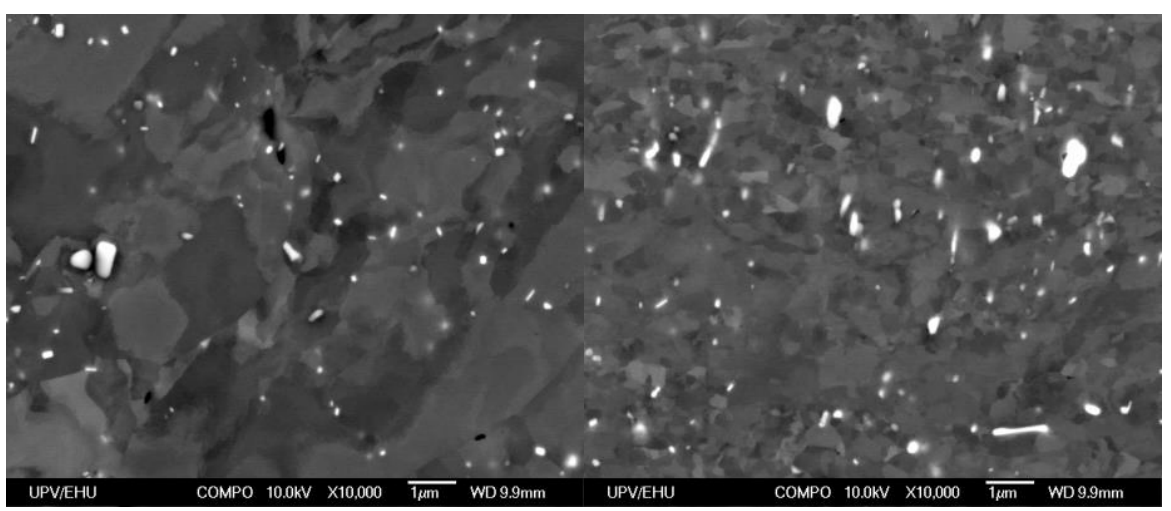

(a)

(b)

Figure 1. SEM micrographs of different isothermally-forged AA5083 states: (a) AA5083 at N0 (annealed); (b) AA5083 at N2 (ECAP-processed). Taken from the research work by León et al. [20].

After being processed by ECAP, the aluminium alloy was isothermally-forged. The forging temperature employed was $200^{\circ} \mathrm{C}$. In this present study, these parts are referred as AA-5083-N2-T200. In order to be able to compare the results obtained with those obtained by using a conventional process, cams of the same aluminium alloy were isothermally-forged from annealed materials at the same temperatures as the ones used for the cams previously-processed by ECAP. These parts are referred in this study as AA-5083-N0-T200. Once these mechanical components were manufactured, a final machining process was carried out on the cams in order to obtain the final shape (see Figure 2 for an outline of the overall manufacturing process of the cams). The dies to obtain the cams and the design process of the cams can be found in a study by Salcedo et al. [21], where the development of ultrafine-grained cams obtained from previously a ECAP-processed material and manufactured by isothermal forging was shown. A comparison between the mechanical properties obtained in the cams manufactured from a material with no previous deformation and with those manufactured from a previously SPD-processed material was also included. However, a study by Salcedo et al. [21] did not deal with the wear behaviour of these mechanical components. Hence, this present research study continued the earlier research works on the analysis of mechanical and microstructure properties of these mechanical components obtained from SPD processes, and, in this present study, the in-service wear behaviour of isothermally-forged cams is shown.

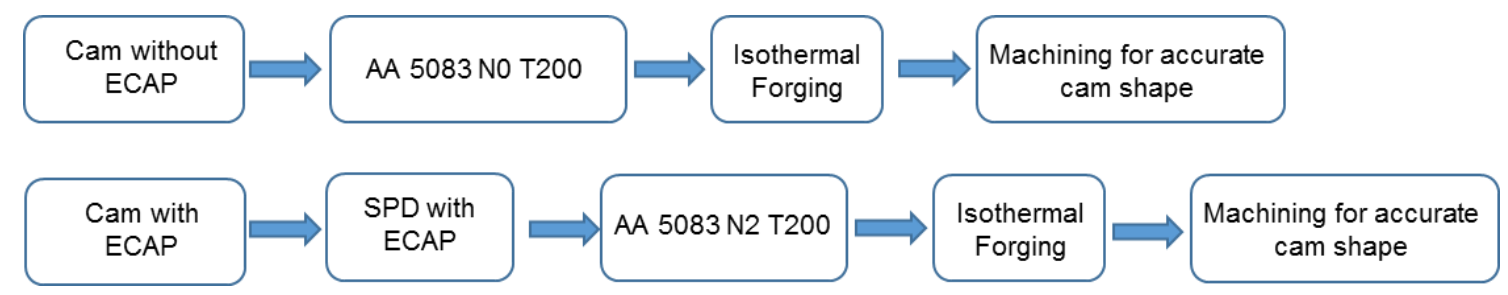

Figure 2. Manufacturing process to obtain the cams with and without previous ECAP processing, where in both study cases, AA5083 was firstly subjected to a heat treatment of annealing.

The main aim of this present study was to determine how an SPD process affects the in-service behaviour of cams with regard to wear. As can be observed in Figure 2, severe plastic-deformed materials and annealed materials were employed in order to manufacture the cams. These thusly manufactured mechanical components were tested in working conditions by using a piece of equipment specifically designed for such a purpose. This equipment, which is installed at the Public University of Navarre, is shown in Figure 3. As can be observed, it may be considered to have a block-on-ring configuration. The equipment to carry out the experimental test in order to determine the wear behaviour of the cams consisted of a cam-follower system. An electric motor drive made the cam 
rotate and so the cam pushed a follower upwards that moved vertically and compressed a spring, which was pre-loaded in order to apply a specific force. To this end, the cam to be tested was placed in the bottom dead centre. Furthermore, it was possible to introduce a preload $\left(F_{0}\right)$ so that the cams could be tested under the desired working conditions.

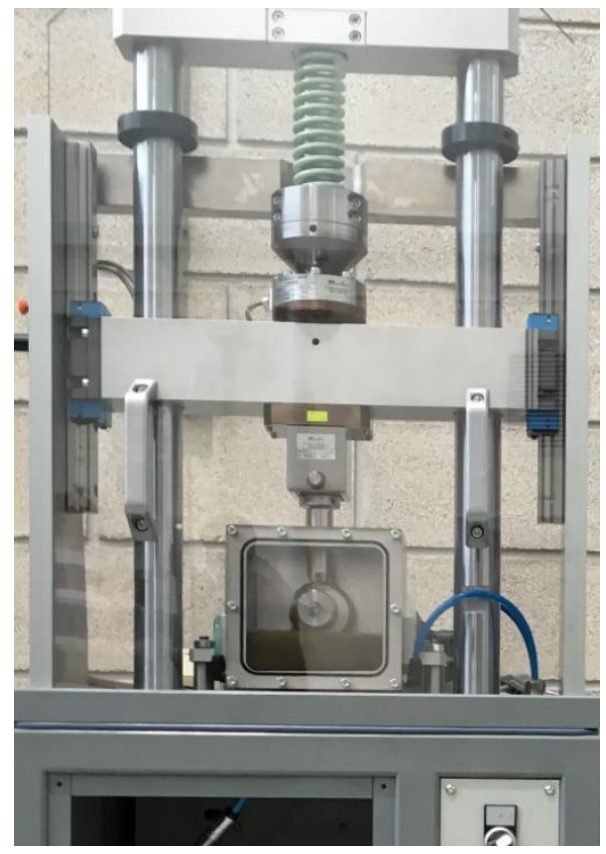

Figure 3. Equipment for testing the in-service wear behaviour of mechanical parts.

As was previously mentioned, a heat treatment of annealing at $345^{\circ} \mathrm{C}$ was first applied to a 5083 aluminium alloy. Then, the cams were manufactured. For the second initial state, the same heat treatment was carried out. Subsequently, it was processed twice by SPD using ECAP and route C at room temperature. The processing velocity was $50 \mathrm{~mm} / \mathrm{min}$. The material was isothermally-forged to obtain the cams at a temperature of $200{ }^{\circ} \mathrm{C}$. Finally, all the cams were machined to obtain the final shape. These cams are shown in Figure 4. In addition, the dimensions and the geometry of the final profile of the radial cam are shown in Figure 5. It was a cam with a stop at $180^{\circ}$ and a distance between top and bottom dead centres of $10 \mathrm{~mm}$.

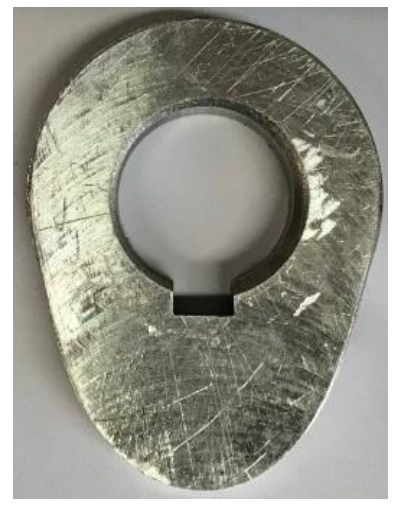

(a)

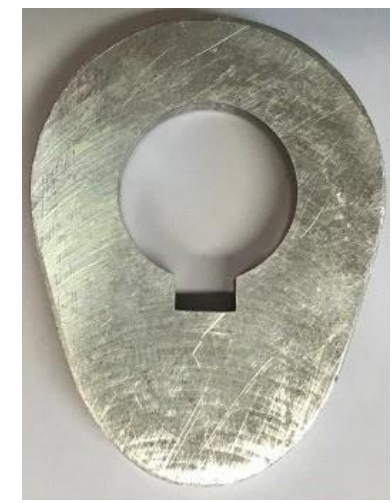

(b)

Figure 4. Cams after the wear tests $\left(200 \times 10^{3} \mathrm{rev}\right)$ : (a) AA5083-N0-T200; (b) AA5083-N2-T200. 


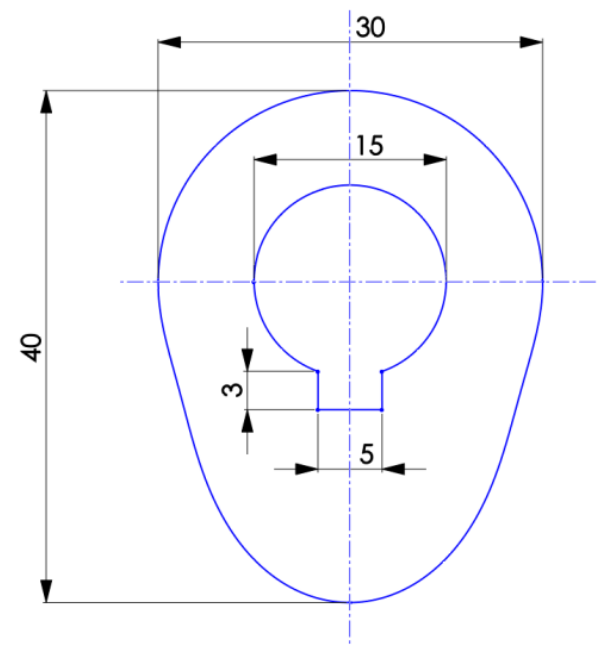

Figure 5. Geometry and final dimensions of the radial cam employed in the wear tests, where the dimensions are expressed in $\mathrm{mm}$.

The cams were placed on the equipment shown in Figure 3, and they were tested under a preload of $100 \mathrm{~N}$, with a spring with a stiffness constant of $10.2 \mathrm{~N} / \mathrm{mm}$ and at a rotational speed of $60 \mathrm{rpm}$. The cams were tested up to $200 \times 10^{3}$ revolutions. The cams were weighed on a precision weighing scale before and after the wear tests at $50 \times 10^{3}, 100 \times 10^{3}$, and $200 \times 10^{3}$ rev in order to determine the volume loss with the functioning time for each of the cams. The precision weighing scale used (Mettler Toledo XS104; Mettler-Toledo, Columbus, OH, USA) has an uncertainty value of $\left(0.04+2 \times 10^{-7} \times\right.$ weight $)$ $\mathrm{mg}$. Three different weight measurements were carried out for each sample at each number of cycles under consideration with the mean values shown in Table 1. An SAE 5W30 oil (Shell, The Hague, The Netherlands) was used as a lubricant for all the cams tested, using new oil for each test so that all wear tests were carried out under the same conditions. The friction couple was composed of AA5083 and hardened steel.

Once the cams were tested following the earlier-mentioned procedure, they were cut in order to be analysed via SEM. Prior to observation, they were cleaned with acetone to remove any remaining spots of lubricant. A JEOL 6400 scanning electron microscope (JEOL, Tokyo, Japan) was used, and the operating parameters were an acceleration voltage of $20 \mathrm{kV}$ and a beam current of around $0.1 \mathrm{nA}$. Secondary electrons were used to obtain the micrographs from the cut samples.

\section{Results and Discussion}

\subsection{Experimental Study of Wear in Isothermally-Forged Cams}

AA-5083-N0-T200 represents the cams obtained from annealed material, and AA-5083-N2-T200 represents those cams obtained from material previously-processed by ECAP. Figure 4 shows the cams of the two initial states considered in this study after the wear tests.

Table 1 shows the volume loss for each of the mechanical components after the wear tests that were carried out following the procedure described in Section 2. The volume loss values obtained were rounded, taking their corresponding uncertainty values $\left(0.05 \mathrm{~mm}^{3}\right)$ into account [22].

Table 1. Loss of volume $\left(\mathrm{mm}^{3}\right)$ during the wear tests, where the expanded uncertainty values are $U$ $(\mathrm{k}=2)=0.05 \mathrm{~mm}^{3}$ for all cases.

\begin{tabular}{cccc}
\hline \multirow{2}{*}{ Study Case } & $\left(\mathbf{5 0} \times \mathbf{1 0}^{3} \mathbf{r e v}\right)$ & $\left(\mathbf{1 0 0} \times \mathbf{1 0}^{3} \mathbf{r e v}\right)$ & $\left(\mathbf{2 0 0} \times \mathbf{1 0}^{\mathbf{3}} \mathbf{r e v}\right)$ \\
\cline { 2 - 4 } & $\left(V_{\text {initial }}-V_{\text {final }}\right)$ & $\left(V_{\text {initial }}-V_{\text {final }}\right)$ & $\left(V_{\text {initial }}-V_{\text {final }}\right)$ \\
\hline AA-5083-N0-T200 & 42.98 & 86.14 & 169.53 \\
\hline AA-5083-N2-T200 & 33.59 & 71.94 & 143.46 \\
\hline
\end{tabular}


As can be observed in Table 1, there was a significant loss of volume during the in-service wear test as a result of the applied force and the number of cycles. However, the parts that were previously-processed using SPD by ECAP were better able to withstand the test conditions than the cams obtained from annealed alloys. This fact was due to the improvement in the mechanical properties of the cam (above all, in microhardness) caused by ECAP. In addition to this, ECAP improved the forgeability, and it thus produced a finer and more homogeneous microstructure in the final cam.

Figure 6 shows the experimental wear results obtained in the cams by measuring the loss of volume with the number of revolutions (since the rotational speed was $60 \mathrm{rpm}$, each of the cams were working under these test conditions for $55.5 \mathrm{~h}$ ).

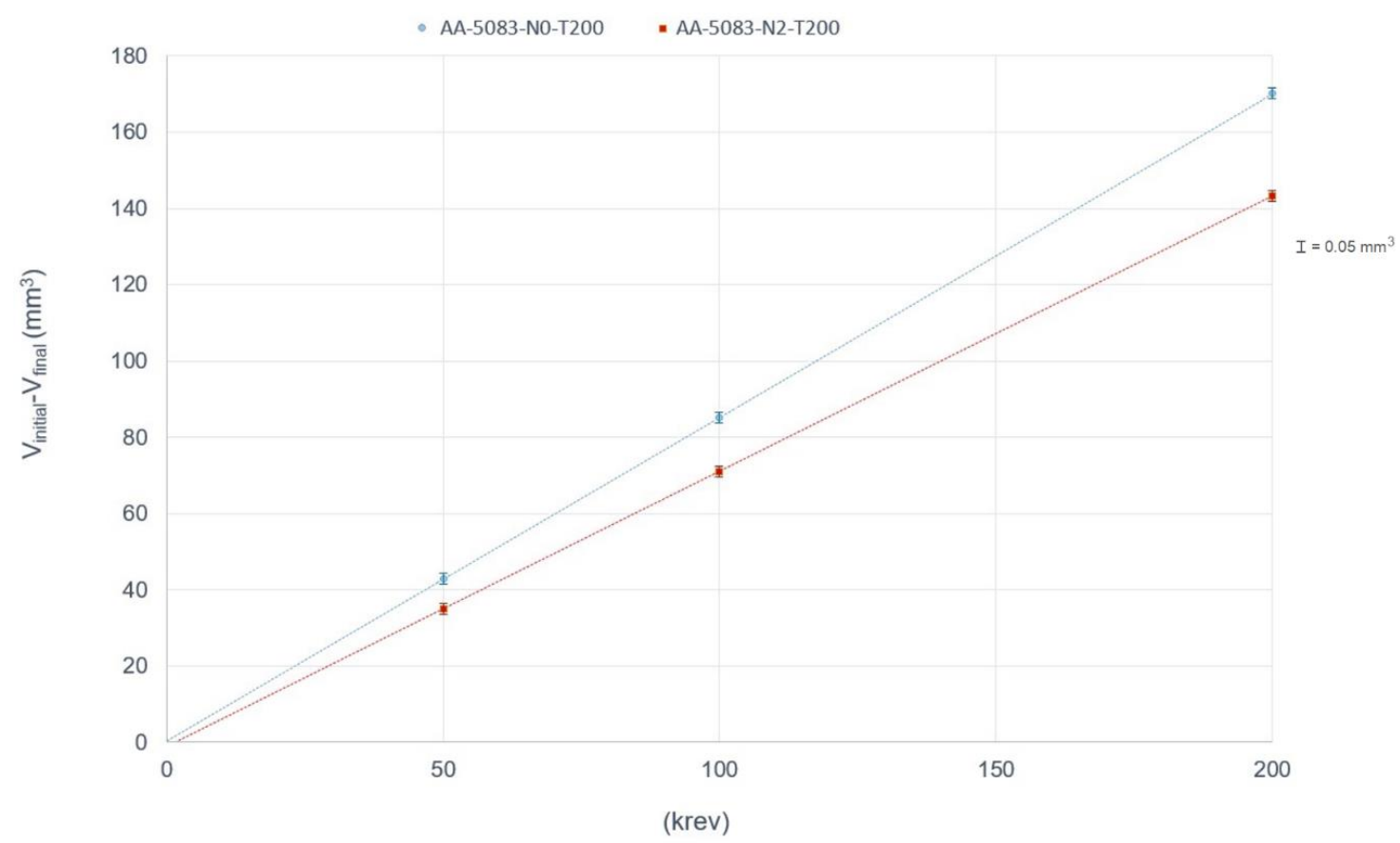

Figure 6. Wear versus revolutions for the isothermally-forged cams, where the scale for the uncertainty values has been amplified as indicated in order to be plotted more clearly.

From the experimental results obtained, it can be affirmed that the wear behaviour was approximately linear ( $\mathrm{R}^{2}$ values of 0.9999 and 0.9997 were obtained for AA-5083-N0-T200 and AA-5083-N2-T200, respectively) under the test conditions that were carried out in this study, and it was found that the cams isothermally-forged from ECAP-processed materials (N2) had lower wear values than those obtained in the cams manufactured from materials that were not previously-processed by ECAP. Specifically, as can be observed in Table 1, the wear of the AA-5083-N2-T200 cam was $15.38 \%$ lower than that obtained in the AA-5083-N0-T200 cam. Hence, for the values obtained in this present study, it was possible to affirm that previous SPD using ECAP improved the wear behaviour of the isothermally-forged cams, mainly because of the improvement in the microhardness that these ECAP-processed cams underwent.

\subsection{SEM Analysis}

The next step was to cut the cams into three different parts so that their worn surfaces could be analysed with SEM. For this purpose, it was decided to conduct the study at the lower and upper zones, as shown in Figure 7, that corresponded to the bottom dead centre and the top dead centre, respectively. 


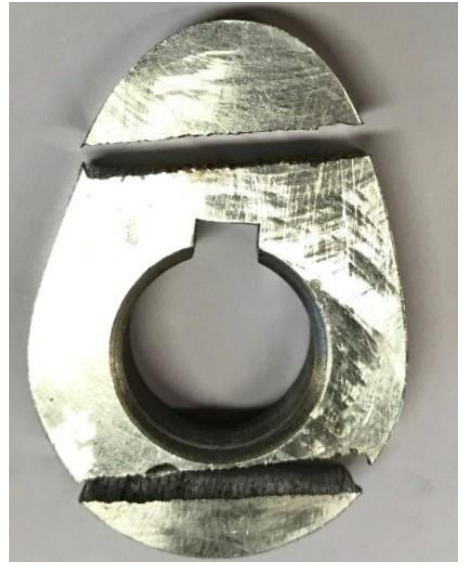

(a)

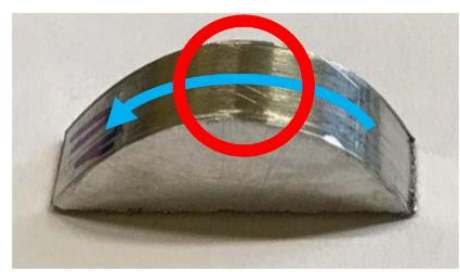

(b)

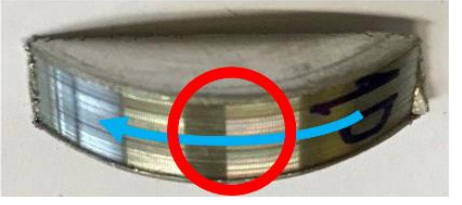

(c)

Figure 7. Study zones of the worn cam (highlighted with red circles), where the blue arrows show the direction of the grooves: (a) cam cut into three parts; (b) upper zone; (c) lower zone.

Figure 8 shows SEM micrographs for the AA5083-N0-T200 cam worn after $200 \times 10^{3}$ rev at two different magnifications of $200 \times$ and $1000 \times$, where the direction of the grooves was parallel to the cam profile plane and was contained in the cam contact surface (see blue arrows in Figure 7).
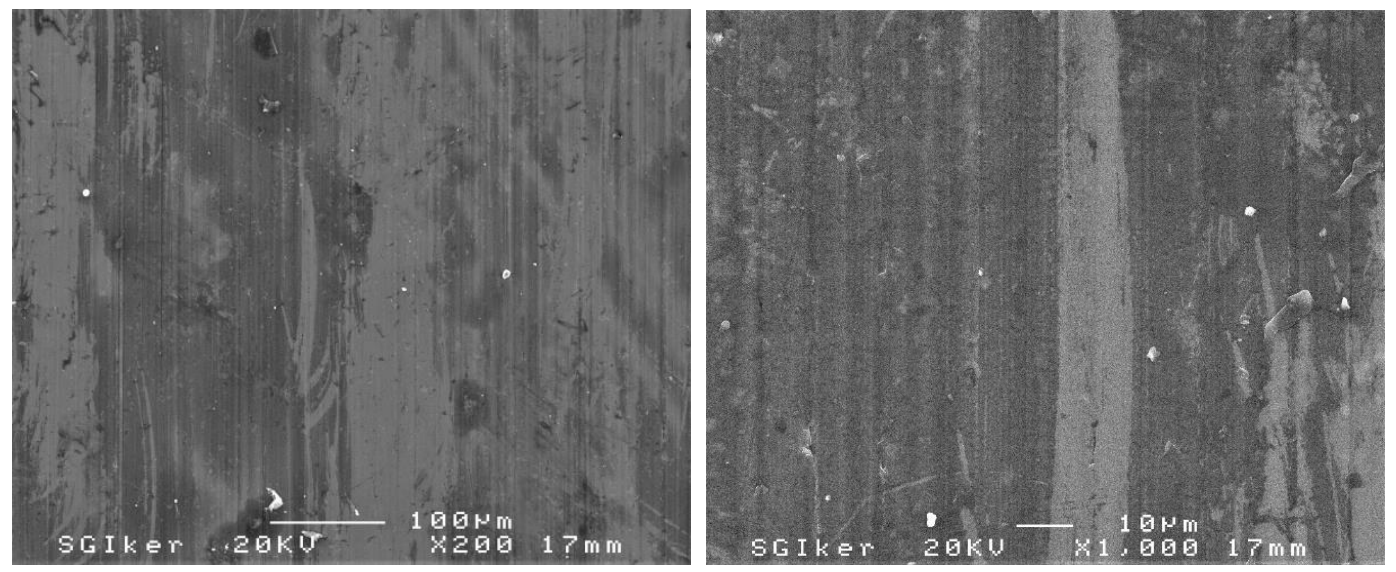

(a)
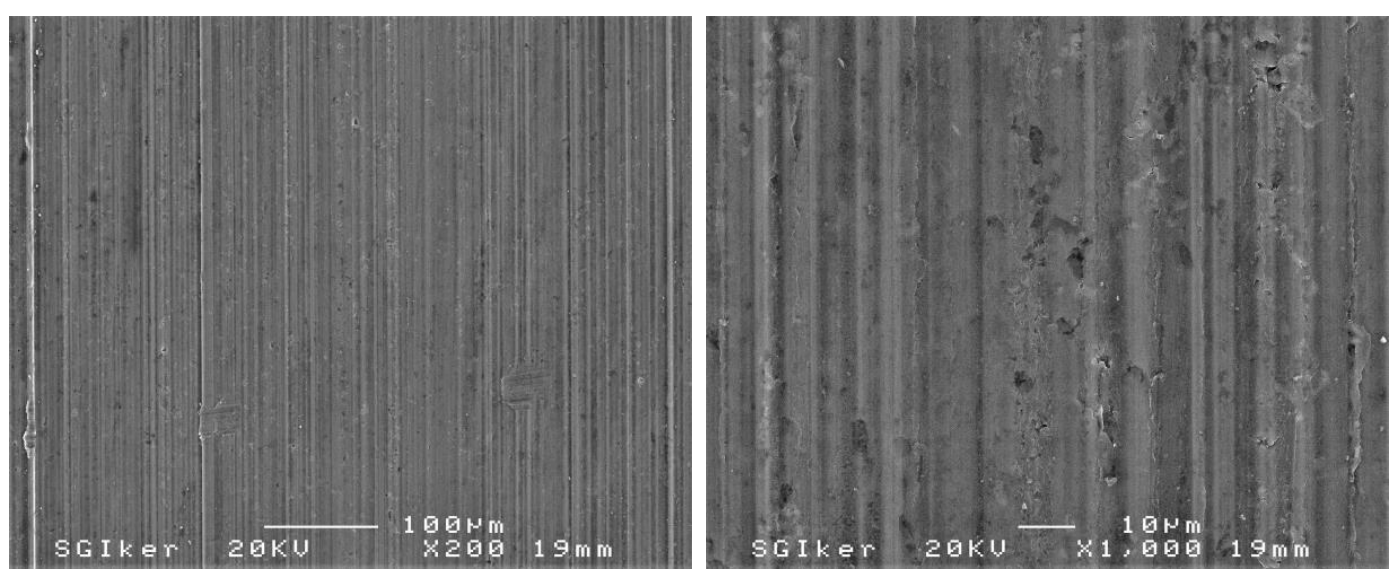

(b)

Figure 8. SEM micrographs that show wear in the AA5083-N0-T200 cam after $200 \times 10^{3}$ rev: (a) upper zone; (b) lower zone. 
In the same way, Figure 9 shows SEM micrographs at 200× and $1000 \times$ of the wear results obtained for the cam of AA5083 isothermally-forged from material that was previously-processed by ECAP once it was tested up to $200 \times 10^{3}$ rev. As in Figure 8, the direction of the grooves observed was parallel to the cam profile plane and was contained in the cam contact surface.
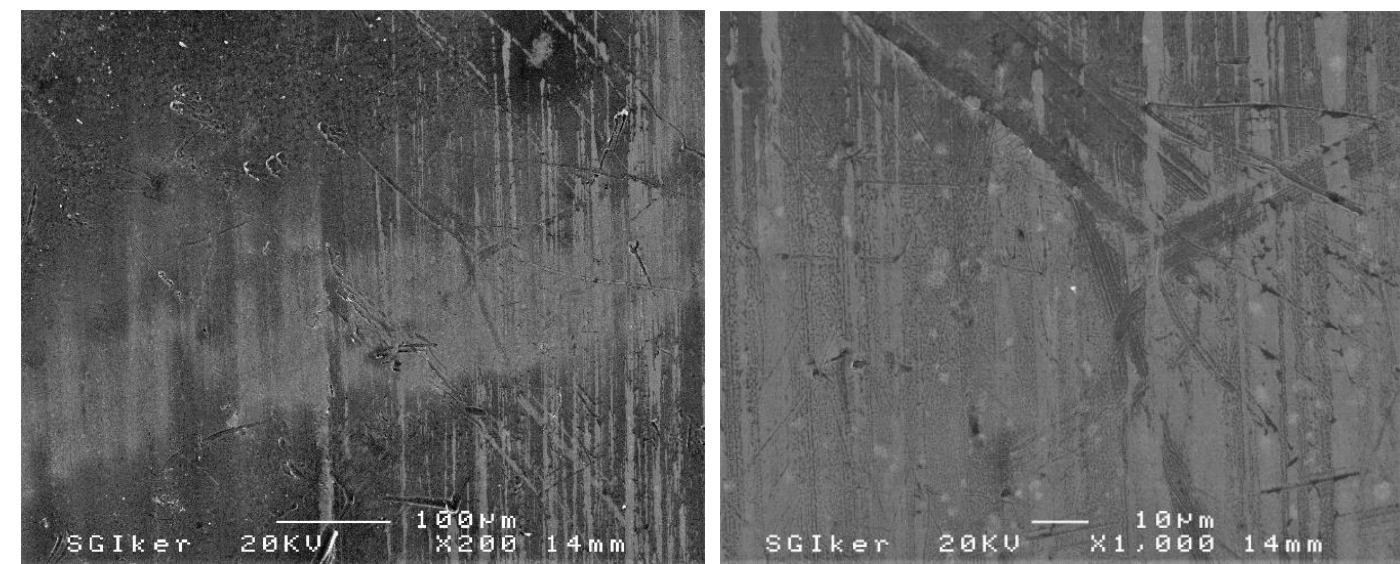

(a)
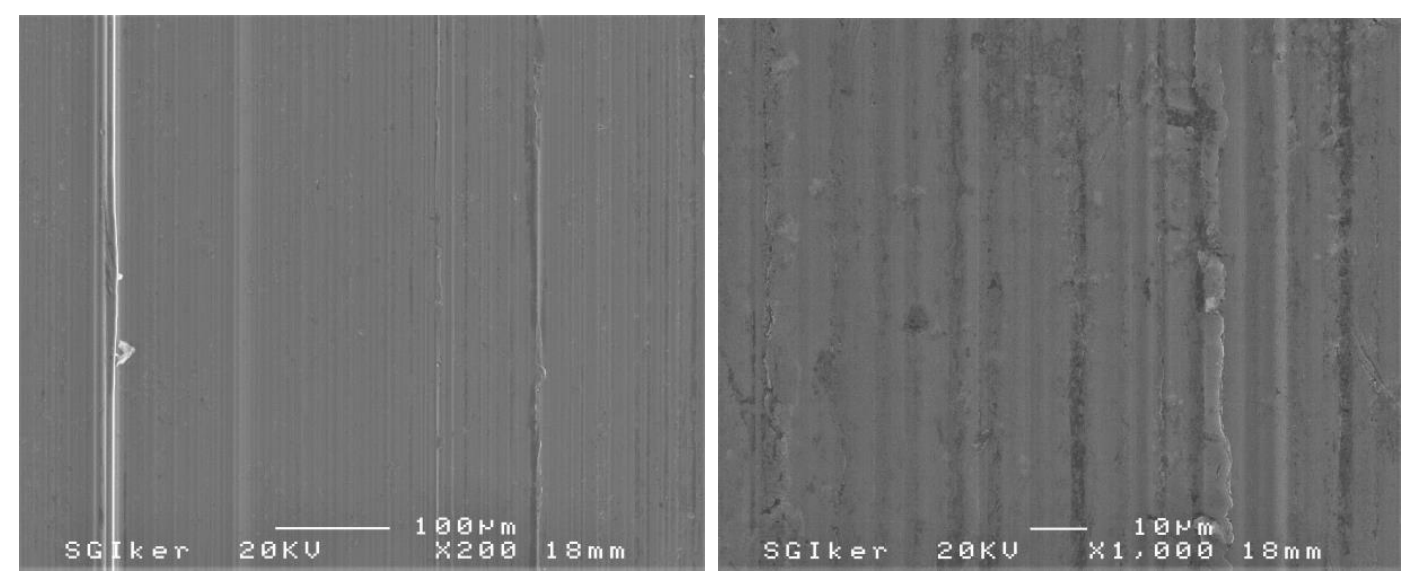

(b)

Figure 9. SEM micrographs that show wear in the AA5083-N2-T200 cam after $200 \times 10^{3}$ rev: (a) upper zone; (b) lower zone.

From a visual inspection, it was not possible to determine the amount of wear, and it was necessary not only to measure it but also to analyse the previous SEM micrographs shown in Figures 8 and 9. Figure 8 (AA5083-N0-T200) shows that at the upper zone (top dead centre), which was the one that holds the highest pressure, the depth of grooves was very small and the width of each groove was barely distinguished. On the contrary, at the lower zone (bottom dead centre), which had a larger contact area, the pressure was lower, and, in this case, the grooves could be seen. Likewise, in Figure 9 (AA5083-N2-T200), it can be seen that at the upper zone, the groove depth was very small. In the lower zone, which had a larger contact area, the pressure was lower, and, in this case, the grooves could be seen, although of little depth and width. If the two different states shown in Figures 8 and 9 (AA5083-N0-T200 and AA5083-N2-T200, respectively) are compared, it may be stated that the wear areas were more pronounced in the case of the cam that had not been previously ECAP-processed (thought this was not easily observed because of the fact that, in both cases, the wear was very high), thus leading to higher wear values in relation to the ECAP-processed cam. This also agreed with the experimental wear results obtained from the measurement of volume loss in the cams tested. Moreover, the results obtained suggest that the cams underwent adhesive wear as a consequence of the force applied. 


\subsection{FEM Study of Wear in Cams}

In order to carry out the finite element modelling, the geometry shown in Figure 10 was used. A transitional meshing was carried out. As such, a smaller element size was used on the contact surface, which was to be in contact with the follower, and a coarser element size was used inside the cam, as shown in Figure 10. The element edge length used in the contact surface between the cam and the follower was $0.0135 \mathrm{~mm}$.

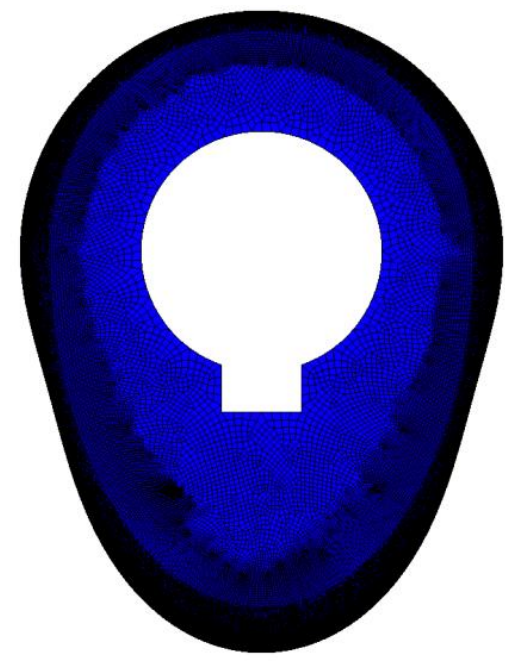

(a)

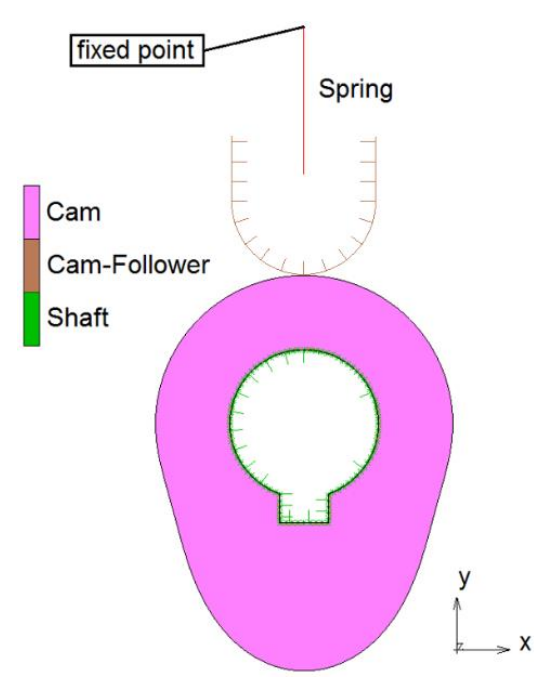

(b)

Figure 10. (a) Meshing of the cam and (b) contact bodies.

Two rigid contact bodies (shaft and follower) and one deformable contact body (cam) were used. Analytical contact boundary descriptions were used in contact bodies to improve the calculation in the contact. Both displacements and rotations were fixed in the follower contact body in all axes except the Y-axis. The FEM software employed was MSC Marc®Mentat@2018 (MSC Software Corporation, Hamburg, Germany) [23]. It is important to indicate that the contact algorithm employed was based on the node-to-segment option. Temperature was not taken into account because in the experimental tests, the cam was submerged in oil and the increase in temperature was not significant. A complete rotation was simulated, and an accumulative lineal behaviour was expected to take place when more cycles were considered. This assumption was justified by the linearity in the lost volume from the experimental tests, which can be observed in Figure 6. Regarding the material, as the study case fell at the elastic part, it was only necessary to use the Young's modulus and the Poisson's coefficient, which were approximately $70 \mathrm{GPa}$ and 0.33 , respectively [24]. The follower was connected to a spring with a stiffness of $10.2 \mathrm{~N} / \mathrm{mm}$, and a non-displacement condition was imposed on the other end of the spring, as shown in Figure 10. A $100 \mathrm{~N}$ preload was imposed on the spring. Moreover, a rotational condition was imposed on the Z-axis, and, in this way, the actual conditions of the wear test shown in previous sections were reproduced. As the cam rotated, it pushed the follower in the Y-direction, which was the only allowed movement for this part so that it compressed the spring. This was done in order to model the behaviour of the wear tests carried out in the equipment shown in Figure 3.

FEM simulations were carried out to analyse the wear of the AA-5083-N0-T200 and AA-5083-N2-T200 cams. In order to carry out this study, the Archard wear model was employed, and the dimensional wear coefficients shown by Table 2 were employed in their respective simulations. These coefficients were obtained from an iterative process. Several FEM simulations were carried out with different $K$ values until the values were obtained that predicted wear with an accuracy of less than $1 \%$ by comparing the loss in volume provided by FEM with that obtained from experimental results. This was done for each of the aluminium alloys. An updated Lagrange procedure and non-linear procedures for large displacements and rotations were used, and a revolution of the shaft 
was simulated. From FEM results, it was observed that when the cam had rotated $180^{\circ}$, it reached the top dead centre, and, at this point, the pressure reached a maximum value, as did the stress value.

Table 2. Dimensional wear coefficients $K\left(\mathrm{MPa}^{-1}\right)$.

\begin{tabular}{cc}
\hline Study Case & $\boldsymbol{K}$ \\
\hline AA-5083-T200-N0 & $6.111 \times 10^{-8}$ \\
\hline AA-5083-T200-N2 & $5.172 \times 10^{-8}$ \\
\hline
\end{tabular}

Figure 11 shows the equivalent Von-Mises stress for $\theta=180^{\circ}$. Wear existed in the contact surface of the cam, and the maximum value of the wear was obtained at the top dead centre-that is, when the cam had rotated $180^{\circ}$, where the equivalent Von-Mises stress was $225.9 \mathrm{MPa}$ (which was also the maximum stress value). From all the forged cams, those which had a lower yield strength were the cams with a starting material at an annealed state (N0). It may be observed in Figure 12, which shows plastic strain values after forging process with the N0 starting material, that at the points where the cam profile appeared after being machined, a plastic strain value between 1.3 and 1.8 was achieved at the N0 state due to the forging process. In [20], it was stated that the yield stress at these strain values was higher than $290 \mathrm{MPa}$. Therefore, the study case fell at the elastic zone of the material, and there was no plastic strain that could have modified the wear mechanism. In this way, an accelerated wear test was achieved, as these stress values were higher than those that appear in a combustion engine. The FEM software employed was MSC Simufact Forming 15.0 (MSC Software Corporation, Hamburg, Germany) [24].

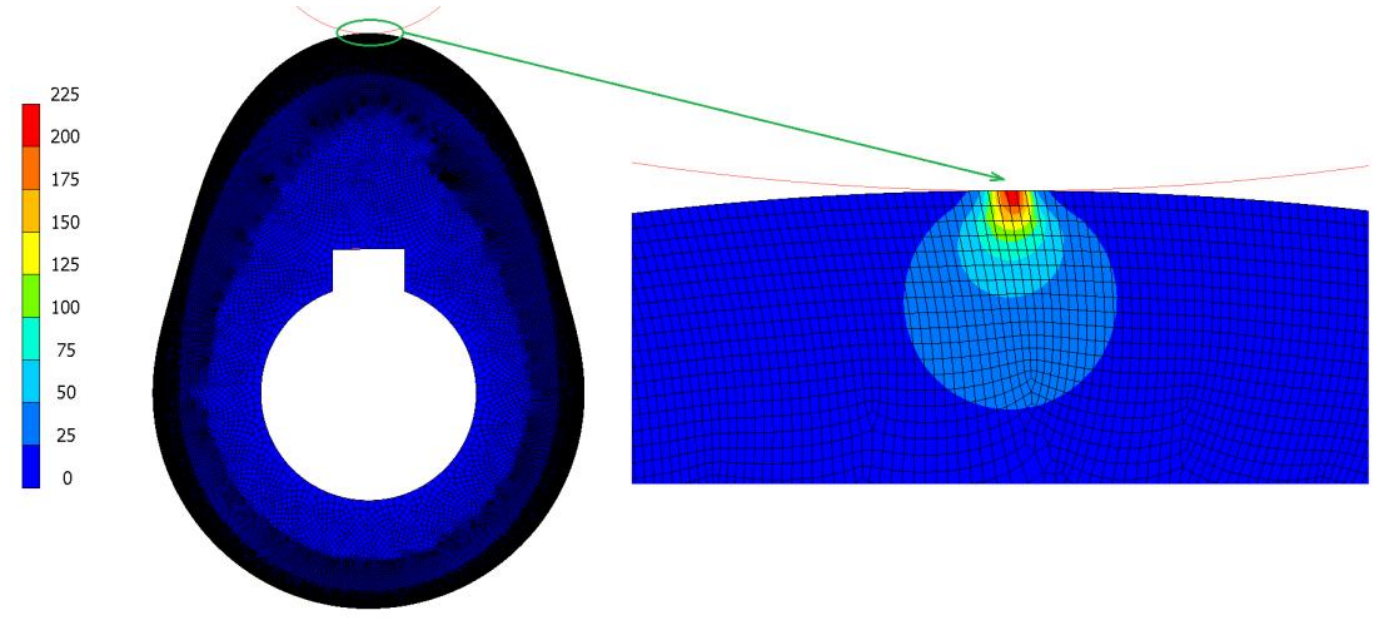

Figure 11. Equivalent Von-Mises stress (MPa) at the top dead centre.

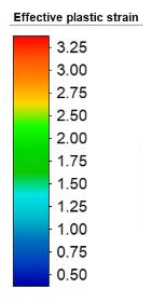

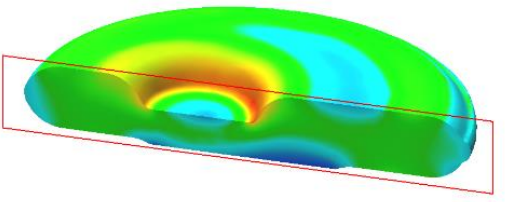

(a)

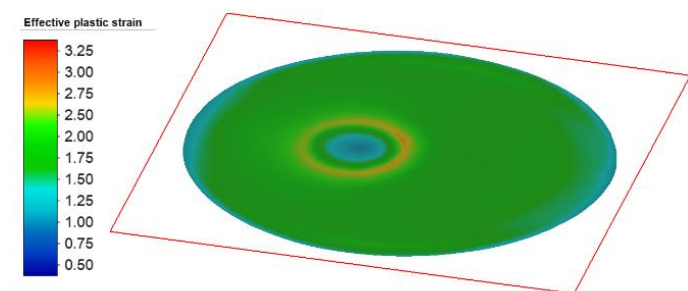

(b)

Figure 12. Effective plastic strain values of cam after the forging process with AA-5083-N0 as a starting material (most unfavourable study case) (a) where the first plane of cut (in red) is a cross-section plane located at the middle of the width of the cam and (b) the second plane of cut (in red) is a longitudinal plane located at the middle of the height of the cam. 
Figures 13 and 14 show the wear index at both the top and bottom dead centre, respectively. These wear index values are a measure of the volume loss due to wear.

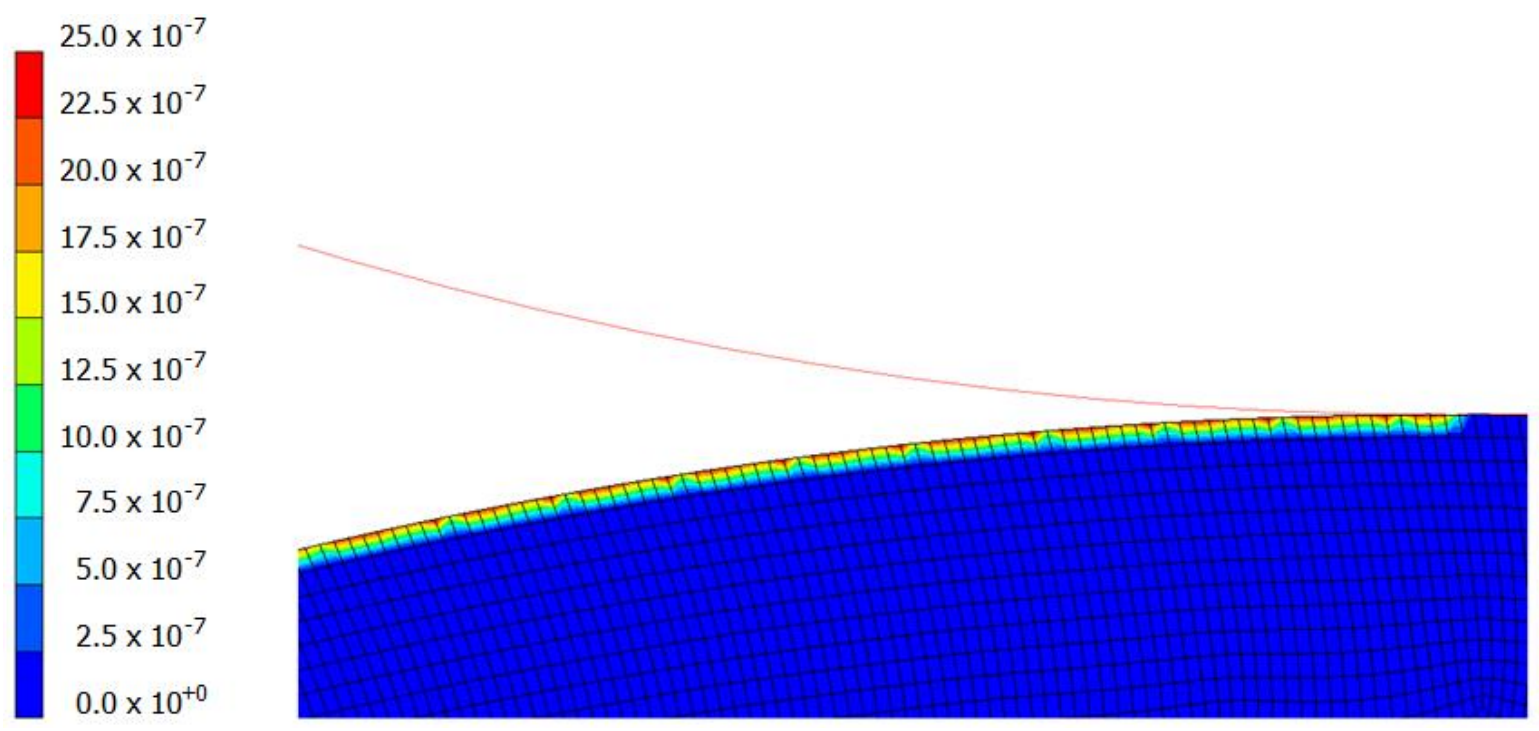

Figure 13. Wear index at the top dead centre for the AA-5083-N2-T200.

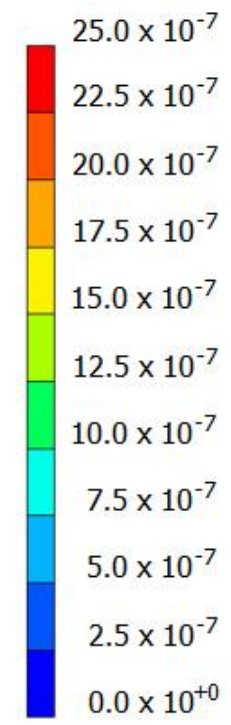

Figure 14. Wear index at the bottom dead centre for the AA-5083-N2-T200.

As can be seen in Table 3, the values obtained by FEM simulation were similar to those obtained experimentally. In this way, it is shown that the FEM methodology that was used in this study is correct and could be employed to estimate the wear on cams both previously-processed by ECAP and without ECAP processing under conditions similar to those of the present study.

Table 3. Comparison of loss of volume $\left(\mathrm{mm}^{3}\right)$ during both the wear tests and FEM, after $200 \times 10^{3}$ rev.

\begin{tabular}{cccc}
\hline Study Case & $\begin{array}{c}\left(V_{\text {initial }}-V_{\text {final }}\right) \\
(\text { Experimental })\end{array}$ & $\begin{array}{c}\left(V_{\text {initial }}-V_{\text {final }}\right) \\
(\text { FEM })\end{array}$ & (FEM vs. Exp) \\
\hline AA-5083-N0-T200 & 169.5305 & 170.7504 & $0.71 \%$ \\
\hline AA-5083-N2-T200 & 143.4624 & 144.5133 & $0.73 \%$ \\
\hline
\end{tabular}




\section{Conclusions}

The cams obtained by previous SPD using ECAP and isothermal forging exhibited better in-service wear behaviour than those that were isothermally-forged from annealed materials at the experimental values under consideration in this study and for the AA5083 aluminium alloy, where this beneficial effect may be explained by the improvement in the microhardness that these ECAP-processed cams underwent.

From the experimental results obtained, it can be seen that the wear behaviour was approximately linear under the test conditions that were carried out in this present research study, and it was observed that the cams previously-processed by ECAP (N2, route C) had lower wear values (in this study case, $15.38 \%$ ) than those obtained with the non-previously-processed alloys (N0).

FEM analysis was used to estimate the wear in both types of cams, and, as a result, a good agreement between both experimental and FEM results was obtained. Several FEM simulations were carried out with different dimensional wear coefficients until values were obtained that predicted wear with an accuracy of less than $1 \%$ by comparing the loss in volume provided by FEM with that obtained from experimental results. The dimensional wear coefficients obtained were $5.172 \times 10^{-8} \mathrm{MPa}^{-1}$ in the ECAP'ed cam and $6.111 \times 10^{-8} \mathrm{MPa}^{-1}$ in the case of the non-ECAP'ed one. The final aim of this study was that these previous values could be used in other FEM simulations in order to estimate wear index and the loss of volume under different conditions of pressure, rotational speed, and with a larger number of cycles. In addition to this, there have been other research studies about the wear behaviour of ECAP-processed materials, but, as far as we know, it is this aspect of performing the wear tests on functional and real mechanical components (in this case, cams), and not on laboratory samples, that makes this present research work novel.

Author Contributions: All the authors of this present manuscript have approximately equally contributed to most of the research tasks. However, C.J.L.P., R.L.I., J.P.F.B., J.L.I., D.S.P., and I.P.A. contributed to a great extent in performing the experiments (investigation); C.J.L.P. and R.L.I. contributed to a great extent in conceiving and designing the experiments as well as in analysing the data (formal analysis), and R.L.I., C.J.L.P., and D.S.P. made the FEM simulations (software). All authors have read and agreed to the published version of the manuscript.

Funding: This research was funded by the Spanish Ministry of Science and Innovation (former Spanish Ministry of Economy and Competitiveness) through the Research Project DPI2013-41954-P.

Acknowledgments: The authors of this present research work acknowledge the support given by the Spanish Ministry of Science and Innovation (former Spanish Ministry of Economy and Competitiveness) through the Research Project DPI2013-41954-P. The authors also thank for technical and human support provided by SGIker (UPV/EHU/ERDF, EU).

Conflicts of Interest: The authors declare no conflict of interest.

\section{References}

1. Valiev, R.Z.; Islamgaliev, R.K.; Alexandrov, I.V. Bulk nanostructured materials from severe plastic deformation. Prog. Mater. Sci. 2000, 45, 103-189. [CrossRef]

2. Zhu, Y.T.; Lowe, T.C.; Langdon, T.G. Performance and applications of nanostructured materials produced by severe plastic deformation. Scr. Mater. 2004, 51, 825-830. [CrossRef]

3. Segal, V.M. Materials processing by simple shear. Mater. Sci. Eng. A 1995, 197, 157-164. [CrossRef]

4. Valiev, R.Z.; Langdon, T.G. Principles of equal-channel angular pressing as a processing tool for grain refinement. Prog. Mater. Sci. 2006, 51, 881-981. [CrossRef]

5. Vorhauer, A.; Pippan, R. On the homogeneity of deformation by high pressure torsion. Scr. Mater. 2004, 51, 921-925. [CrossRef]

6. Huang, J.; Zhu, Y.T.; Alexander, D.J.; Liao, X.; Lowe, T.C.; Asaro, R.J. Development of repetitive corrugation and straightening. Mater. Sci. Eng. A 2004, 371, 35-39. [CrossRef]

7. Ivanisenko, Y.; Kulagin, R.; Fedorov, V.; Mazilkin, A.; Scherer, T.; Baretzky, B.; Hahn, H. High Pressure Torsion Extrusion as a new severe plastic deformation process. Mater. Sci. Eng. A 2016, 664, 247-256. [CrossRef]

8. Kim, W.J.; Sa, Y.K.; Kim, H.K.; Yoon, U.S. Plastic forming of the equal-channel angular pressing processed 6061 aluminum alloy. Mater. Sci. Eng. A 2008, 487, 360-368. [CrossRef] 
9. Luis Pérez, C.J.; Salcedo Pérez, D.; Puertas Arbizu, I. Design and mechanical property analysis of ultrafine grained gears from AA5083 previously processed by equal channel angular pressing and isothermal forging. Mater. Des. 2014, 63, 126-135. [CrossRef]

10. Lee, J.H.; Kang, S.H.; Yang, D.Y. Novel forging technology of a magnesium alloy impeller with twisted blades of micro-thickness. CIRP Ann. 2008, 57, 261-264. [CrossRef]

11. Ortiz-Cuellar, E.; Hernandez-Rodriguez, M.A.L.; García-Sanchez, E. Evaluation of the tribological properties of an Al-Mg-Si alloy processed by severe plastic deformation. Wear 2011, 271, 1828-1832. [CrossRef]

12. Thiyaneshwaran, N.; Sureshkumar, P. Microstructure, mechanical and wear properties of aluminum 5083 alloy processed by equal channel angular extrusion. Int. J. Eng. Res. Technol. 2013, 2, 17-24.

13. Chegini, M.; Fallahi, A.; Shaeri, M.H. Effect of Equal Channel Angular Pressing (ECAP) on wear behavior of Al-7075 alloy. Procedia Mater. Sci. 2015, 11, 95-100. [CrossRef]

14. Li, J.; Wongsa-Ngam, J.; Xu, J.; Shan, D.; Guo, B.; Langdon, T.G. Wear resistance of an ultrafine-grained Cu-Zr alloy processed by equal-channel angular pressing. Wear 2015, 326, 10-19. [CrossRef]

15. Luri, R.; Luis, C.J.; León, J.; Fuertes, J.P.; Salcedo, D.; Puertas, I. Analysis of Fatigue and Wear Behaviour in Ultrafine Grained Connecting Rods. Metals 2017, 7, 289. [CrossRef]

16. Avcu, E. The influences of ECAP on the dry sliding wear behaviour of AA7075 aluminium alloy. Tribol. Int. 2017, 110, 173-184. [CrossRef]

17. Wang, Y.F.; Yang, Z.G. Finite element model of erosive wear on ductile and brittle materials. Wear 2008, 265, 871-878. [CrossRef]

18. Spiegelberg, C.; Andersson, S. Simulation of friction and wear in the contact between the valve bridge and rocker arm pad in a cam mechanism. Wear 2006, 261, 58-67. [CrossRef]

19. Shirzadegan, M.; Almqvist, A.; Larsson, R. Fully coupled EHL model for simulation of finite length line cam-roller follower contacts. Tribol. Int. 2016, 103, 584-598. [CrossRef]

20. León, J.; Luis, C.J.; Juan, P.; Fuertes, I.P.; Rodrigo, L.; Daniel, S. A Proposal of a Constitutive Description for Aluminium Alloys in both Cold and Hot Working. Metals 2016, 6, 244. [CrossRef]

21. Salcedo, D.; Luis, C.J.; Luri, R.; Puertas, I.; León, J.; Fuertes, J.P. Design and Mechanical Properties Analysis of AA5083 Ultrafine Grained Cams. Metals 2017, 7, 116. [CrossRef]

22. Evaluation of Measurement Data-Guide to the Expression of Uncertainty in Measurement (GUM); BIPM: Sèvres, France, 1995.

23. Marc $^{\circledR}$ Mentat $^{\circledR}$ 2018; MSC Software Corporation: Hamburg, Germany, 2018.

24. Simufact Forming 15.0; MSC Software Corporation: Hamburg, Germany, 2018. 